\title{
Developing a geologic 3D panoramic virtual geological field trip for Mudeung UNESCO global geopark, South Korea
}

\author{
Department of Earth Science, Kongju National University, 56 Kongju-Daehak-Ro, Kongju, Chungnam 314-701, Korea; \\ *Corresponding author, E-mail: tephra@kongju.ac.kr
}

(Received: May 13, 2019; Revised accepted: July 31, 2019)

https://doi.org/10.18814/epiiugs/2019/019019

We tested a new method for creating virtual geological field trips by using $3 D$ panoramic virtual reality (PVR) techniques to develop a program exploring Mudeung UNESCO Global Geopark, South Korea. The geological features of the Mesozoic Cretaceous rocks include dinosaur footprints of the Jangdong Formation, beautiful Hwasun Cliff, Mudeung Tuff and quartz granite. The Mt. Mudeung is a progressive model of the Mesozoic igneous activity and is an excellent geological study area. This paper provide information on the development, organization, content, interactive controls, and other key aspects of the geological filed trips and landscapes. The $360^{\circ} \times 180^{\circ}$ model can be accessed via PCs or smartphones and be freely rotated and zoomed. This method allows rapid virtual exploration of the area's geological features, allowing students to explore the local strata and other information. It also assists student learning by providing enlarged interactive images, pop-up windows with additional information, and expert explanations of important observational points. Programs of this type can be used as remote learning materials that address common problems with physical geological field trips like cost, safety, and distance to enhance earth science at many levels.

\section{Introduction}

Laboratory sessions and field trip observations are both essential activities in Earth Science education, but the potential scope of geological field trips can be extremely limited due to difficulties including the lack of a fully developed field course, overpopulated classes, distance and time required, and cost (Caliskan, 2011; Allison and Cuffey, 2012). At the middle school, high school, and university levels, field trips can sometimes be replaced by model experiments using rock, mineral, or fossil samples; alternatively, narrowly focused field trips can be conducted during the weekend or a specific time frame (Kim and Lee, 2011). The 2011 educational reforms introduced in South Korea (Ministry of Education, 2011) emphasized creative field work in all courses and included content on the "Beautiful Peninsula" to build student understanding of the connections between South
Korea's main tourist attractions, geography, and geology. However, these reforms are focused on resources that present geological structures and geography only in pictorial form (such as may appear in textbooks), limiting students' ability to fully understand the geological context (Kim et al., 2013; Cheon and Kim, 2018).

One solution to this problem is Panoramic Virtual Reality (PVR) field courses using 3D technology; these can present a virtual 3D world with minimal cost and technology, unlike standard virtual reality approaches. Previous research on Virtual Field Trips (VFTs) has argued that VFTs provide the essential nature of field trips online by allowing independent learning, chronological or non-chronological access to resources, and the inclusion of diverse information beyond strictly geological content (Hurst, 1998; Qiu and Hubble, 2002; Park et al., 2008; Caliskan, 2011; Uricchio, 2011; Allison and Cuffey, 2012). These experiences can also be accessed anywhere by anyone using smartphones.

In this study we explored ways to apply VFT in multiple situations, including developing a web-based PVR field trip focused on volcanic topography and geology for earth science students. This educational content can be accessed in a customized order so that students can control their learning pace based on their capacities; there are no space or time restrictions and little economic burden, while the same place can be explored repeatedly.

\section{Geologic Background and Field Trip Program}

Mt. Mudeung $(1,187 \mathrm{~m})$ in souestern South Korea is widely known for its well-developed and massive columnar jointing at elevations $>700 \mathrm{~m}$ above sea level. This is expressed in numerous prominent and well-known individual colonnades, including Seoseok-dae, Ipseokdae, and Gwangseok-dae on the main summit and Sinseon-dae on northeastern secondary summit. Among the prominent colonnades, Seoseok-dae, Ipseok-dae and Gwangseok-dae are particularly well known for their massive and distinct columnar joints. The massive columnar joints in Ipseok-dae, Gwangseok-dae, and Sinseon-dae are with an average diameter of $1 \sim 2 \mathrm{~m}$ and height of $2 \sim 3 \mathrm{~m}$ (Oh et al., 2012). The massive columnar joints in Ipseok-dae, Gwangseok-dae, and Sinseon-dae are with an average diameter of 3 to $6 \mathrm{~m}$ and height of 2 to $3 \mathrm{~m}$. Seoseok-dae and top area are with diameter below $1 \mathrm{~m}$ and 
height below $2 \mathrm{~m}$ and are relatively smaller than Ipseok-dae and Gwangseok-dae. They are relatively small since the contraction by freezing in the upper portion was expanded to the lower portion rapidly (Oh et al., 2012).

Mt. Mudeung contains various igneous rocks from the Precambrian to the Cretaceous. Mt. Mudeung mostly consists of widespread lava emplacements intruded by Bulguksa granite (Kim, 1998; Kim et. al., 1993). The igneous rocks of Mt. Mudeung are classified as Precambrian-Mesozoic granitic gneiss. Igneous activities in the area were initiated by the intrusion of Precambrian gneissic granite and continued with the intrusion of Gwangju granite from the Late Triassic to Early Jurassic. This is thought to have been caused by the Songrim disturbance. Consequently, small-scale Gwangju porphyritic granite formed in western Mt. Mudeung (Kim et al., 1993; Cha, 1988; Kim et al., 2013). Igneous activities were relatively weak during the Middle Jurassic, which is consistent with an intermission in igneous activities in the Korean Peninsula; only a small-scale intrusion of Jurassic quartz diorite occurred in southeastern Mt. Mudeung (Lim et al, 2015).

Large-scale volcanic activities in Mt. Mudeung and its adjacent regions began during the Cretaceous. During the Early Cretaceous, tuff deposition and lava flows, comprising andesite, dacite, and rhyolite, occurred. In the Late Cretaceous, plutonic rocks consisting of micrographic granite and pink feldspar granite intruded first, followed by intermediate-acid dike rocks along the ruptured area. All magmatism is thought to be relevant to the contraction of magma chambers (Cha, 1988; Park et al., 2005; Ahn, 2010).

Granitic gneiss in the base of Mt. Mudeung and amphibole-biotite granodiorite in the upper strata of the metamorphic Pyongan system are distributed as small-scale intrusions in the western foot of the mountain and the southern Hwasun region. Coarse-grained sheets containing relatively large amphibole crystals and medium-texture sheets with finegrained pillows or columnar jointed amphibole occur in these regions (Cha, 1988; Park et al., 2005; Ahn. 2010; Lim et al., 2015). Coarsegrained sheets are prone to deuteric alteration, whereas medium-texture sheets are significantly altered. Quartz, plagioclase, biotite, and amphibole are the major minerals, and zircon, apatite, spinel, and other opaque minerals are the minor minerals (Kim et al., 2013). Quartz diorite in southeastern Mt. Mudeung exists as small rock blocks. The rock edge is dark gray or midnight blue, and the center is lighter (pinkish or plain gray), an indication of more mafic minerals occurring in the rock edge. Plagioclase, general pyroxene, hypersthene, biotite, quartz, and magnetite are the major minerals, and epidote and chlorite are the minor minerals (Kim et al., 2012; Kim et al., 2013). Hwasun andesite is composed of andesitic tuff and lava as well as intrusive rocks. Andesitic tuff contains light-green rock fragments $(5-10 \mathrm{~mm})$ and purplish brown pumice from lapillus (coarse) tuff. Andesitic lava emplacement consists of multiple lava layers, implying multiple lava eruptions. Its color is normally dark green or dark gray and brown or reddish brown under weathering conditions. Most andesites have no phenocrysts. However, phenocrysts, amygdaloidal structures, or even slight flow structures are observed in some cases. The amygdaloidal structure is elliptic and composed of calcite, chlorite, and chalcedony. Most phenocrysts comprise plagioclase, but some include other colored minerals. Hwasun andesite consists of plagioclase, hyaline, and chloritized colored minerals; micro crystalline crystals are spread in the hyaline base (Kim et al., 2012; Kim et al., 2013). Dogok rhyolite contains well-developed flow structures. It covers or intrudes into the Hwasun andesite, yielding an unconformity. The flow structure usually comprises the alternation of red and light-colored lines with thicknesses of 2-5 mm. Plagioclase and biotite are castable but magnetite and rutile are not. The red lines of the flow structures comprise cryptocrystalline or hyaline, whereas the white lines consist of microcrystalline quartz.

Mudeung tuff from Mt. Mudeung is dark gray in color and classified as lava with porphyroblastic fabric. It intrudes into quartz porphyry and micrographic granite and has partially developed flow structure and numerous columnar joints. Phenocrysts consist mostly of plagioclase but, in some cases, contain quartz and amphibole or even andesite. Plagioclase phenocrysts have a semitransparent light-gray color, with sizes of 1-5 mm. Weak welded structures are observed in the hyaline basis. This indicates that some quartz andesite may have been formed by welded tuff (Kim et al., 2012; Kim et al., 2013; Lim et al, 2015). Quartz porphyry is light gray or lemon yellow in color and contains quartz and feldspar. It is a circular dyke with a width of 300 $\mathrm{m}$, intruding almost vertically along the boundaries of the Hwasun and quartz andesites of Mt. Mudeung. Quartz, plagioclase, orthoclase, and biotite are the major minerals, and magnetite is the minor mineral (Kim et al., 2013; Lim et al., 2015).

Micrographic granite is red or light red and disturbed by the intrusions of all the rock layers mentioned above. Micrographic granite consists of quartz, orthoclase, plagioclase, and biotite as major minerals and amphibole, magnetite, apatite, and zircon as minor minerals. Quartz forms intergrowths with orthoclase to from the micrographic structure. Biotite has been chloritized, and particulate magnetite is arranged along the cleavage (Kim et al., 2012; Kim et al., 2013).

Acidic and intermediate dykes occur, with the latter being dominant. The former includes quartz veins, felsites, and pegmatite dykes and the latter porphyritic and massive andesites, both of which are currently being produced (Kim et al., 2013; Lim et al., 2015).

Mt. Mudeung was nominated as a UNESCO Global Geopark in 2018 through the efforts of the provincial government, civic organizations, and civilians in the nearby city of Gwangju (Fig. 1). The filming location was the same area in which the geological field trip program was developed. We used a camera with a fish-eye lens for shooting in $360^{\circ}$.

\section{Methods}

\section{Stitching and Creation of the VFT Program}

PTGui and PanotourPro software were used to stitch the filmed photographs into one panoramic image with consideration of camera compatibility (Figs. 2 and 3).

The VFT program was created by adding educational elements, such as pre-recorded explanations of the geology and links to further content, to the completed panoramic image. The production process is represented by images 6-9, while the main screen of the completed program is shown in image 10. Each location is connected to a map and the view direction is clearly marked, making it possible to identify the location being studied. An observation point list allows the 


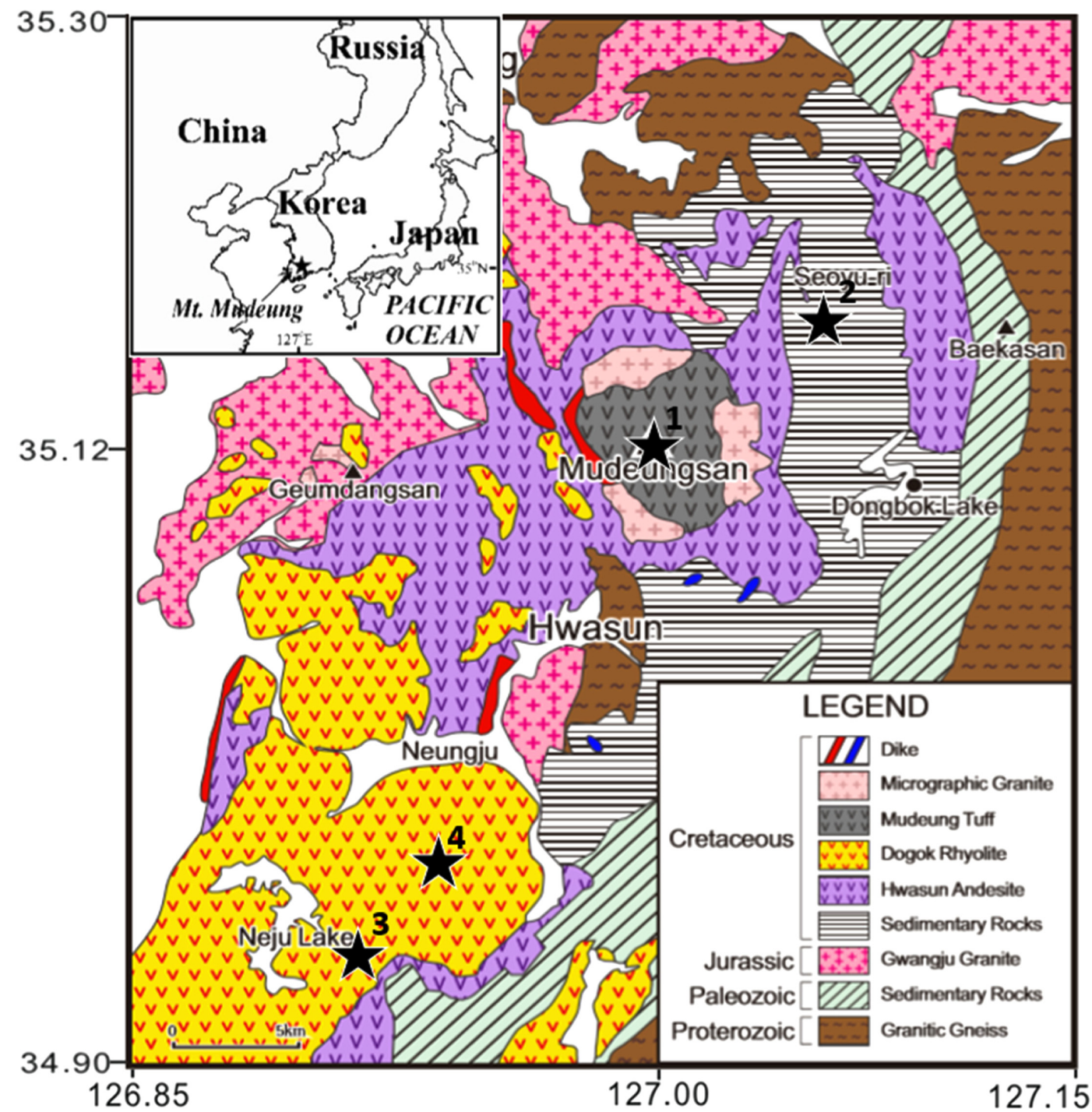

Figure 1. Location and geological map of main observational points from Mudeung UNESCO Global Geopark area, modified from Lim et al., 2015. Each Star's number is used for creating virtual geological field trips by using 3D panoramic virtual reality (PVR) techniques in the UNESCO Global Geopark, South Korea. The field area is Star marking 1; the columnar joint in Mt. Mudeung and Deoksan Stony Slope, Star marking 2; Hwasun Dinosaur Fossil Site, Star marking 3; Unjusa Temple Stratiform Tuff, and Star marking 4; Hwasun Dolmen Site Jangdong tuff research area.

learner to navigate between points. A hotspot feature provides supplementary educational material such as a relevant link or audio guide, enabling independent learning (Kim, 2014).

\section{Results and Discussion}

\section{Practical Use of VTF}

\section{Deoksan Stony Slope}

Stony Slope is also called a "tallus" and refers to a pile of stones that columnar joint or a mass of rock is crashed by weathering and flowed down along the slopes of a collapsed mountain. Deoksan Stony Slope is produced between 350 and $700 \mathrm{~m}$ above sea level on the western slope side of the ridge connecting central peak to Donghwasa temple site.
At the end portion of Stony Slope, a mineral water source appears, and the mineral water corresponds to the upstream where the tributary of Jeungsimcheon originate.

The columnar joints that form the Deoksan Stony Slope were formed when the columnar joint cliff of Mudeung tuff (dacitic tuff) at Mt. Mudeung, located between Dongwhasa temple site and central peak, was collapsed. The length of Stony Slope is about 600 meters and the width reaches 250 meters. The average slope of Stony Slope is formed steep slope with $25^{\circ}$ to $35^{\circ}$ and the slope sides are generally flat and wide, however, it has a slight concave shape at middle part (Oh et al., 2012).

The Deoksan Stony Slope, it is appeared not only the dacitic tuff rock block, but also quartz porphyry property together. It is possible to see that these quartz porphyry properties are moved along the slope together with the dacitic tuff. This is because that quartz porphyry is shown at the region of in Deoksan Stony Slope. It means that the 


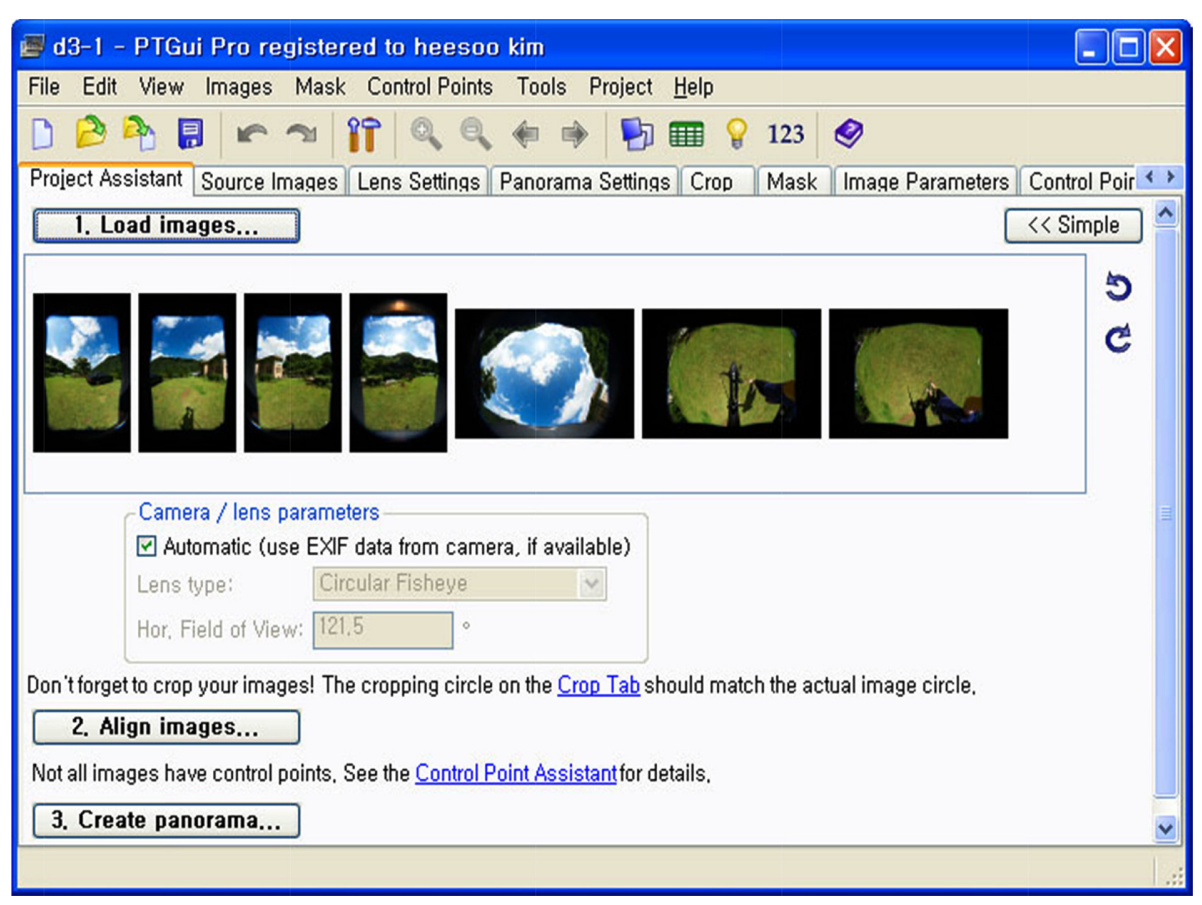

Figure 2. Example of PTGui photo-stitching software. PTGui software (Image gallery and panorama editor) is image stitching software for stitching photographs into a seamless 360-degree spherical or pixel panoramic image.

upper portion of quartz andesite and quartz porphyry were came in together in periglacial period. It is observed that the ratio of the Mudeung tuff is relatively high. The Mudeung tuff forms a circular shaped edge of rock block and has somewhat brighter gray color compared to quartz porphyry. The Mudeung tuff has a developed joint compared to the middle portion of Deoksan Stony Slope, and there are many cracked rock fragments along the joint.

Deoksan Stony Slope is thought to be formed about 50,000 years ago, and the slope has a convex shape at the upper portion and a concave shape at the middle portion (Kim et al., 1988; Oh et al., 2012). Subsequently, it can be observed that the lower portion of the slope is convexed again. The convex shape of the slope lower portion shows similar trend to the characteristics of the slope observed in the Stony Slope region in the periglacial climate environment. The convex shape at the lower portion of the slope is because the soil and some of the rock block are pushed out when the weight of the rock block that used to be with the soil is concentrated at the lower portion. It shows a high degree of slope at the middle portion of Stony Slope. The reason for this is estimated that rock blocks and fine-grained materials flowed down from the upper portion were piled thick, and then the fine-grained materials are removed from the warm and humid climate environment, occurring the sinkage of the rock block. Such a sinkage geography is also being seen in small scale at many places of Stony Slope.

From the positional characteristics of the Deoksan Stony Slope rock block, in case of the upper portion, the rock block has a smooth surface compared to the lower portion, and the characteristic of the rock block crystal is clearly observed. In the rock block, there are few joints, and even if the joint is observed, it is the shape with little splitting. Some rock blocks of this portion are interconnected, but the rock blocks that exist independently on the matrix are also distributed around (Oh et al., 2012).

Deoksan Stony Slope is a large scale site which can be observable even in downtown of Gwangju, providing data on the topography formed by weathering. It is a good geo-site that informs the environmental changes from exposure to the formation of Stony Slope due to weathering since periglacial period. All of this 3D panoramic virtual reality (PVR) program is available from a website (http:// 203.253.36.216/hskim/panorama/mudng-mai/ md.html) by PCs or smartphones and be freely rotated and zoomed.

\section{Hwasun Dinosaur Fossil Site}

Hwasun Dinosaur Fossil Site is located in the Oncheon district, Hwasun, northwest of Hwasun-Gun, Jeonnam-Do, corresponding to the southeast slope of the Mountains stretching northeast from Mt. Mudeung. This fossil site has its importance as the first dinosaur footprints fossil site found in the inland of Jeonnam-Do (Huh et al., 2003). In the region where Jangdong layer (Jangdong tuff) of Neungju basin, one of the terrigenous sedimentary basin in the Cretaceous period of the Mesozoic period, is distributed, fossils of well-preserved dinosaur footprints, including more than 70 dinosaur trackways, have been reported. Most of them are the footprints of meat-eating dinosaur (deinonychosaur), and have a characteristic that is found very long and intensively in a single region. In addition, this corresponds to a rare case in the world (average trackway maximum), and is a valuable academic data that can recognize the ecological environment of the dinosaurs during the Cretaceous period (Huh et al., 2003; Paik, 2010). Dinosaur footprints fossils are produced at sandstone and mudstone, which are alternated with lamination layer or thin layers formed by stratiform flooding in a mudflat environment around a lake with subarid climatic conditions, and various sedimentary structures, such as ripple mark and mud crack, are often observed in these rock floors. Meanwhile, Paik et al. (2010) recently proposed acceleration theory by interpreting behavioral characteristics of deinonychosaur dinosaur based on the fossil of their trackway in this region.

This region corresponds to one of 5 regions of the Korean Cretaceous Period's Dinosaur Coast (KCDC: Cretaceous Dinosaur Coast), included in the UNESCO World Heritage Temporary List, and was designated as Natural Monument No. 487 on November 9, 2007, to preserve the academic and natural historical value.

Hwasun Dinosaur Fossil Site belongs to the Jangdong layer (Jangdong tuff) of Jangdong layer group, formed in the Cretaceous period of the Mesozoic period, geologically. The strike and slope of sedimentary layer where the fossils were found are N30-40E, 20-30SW, and in general, the extensity of stratification is good. Rock floor shows an alternation or interlaminated layer with sand stone or silt stone and mud stone, and assembly or fine-grained sand stone with 10 to $50 \mathrm{~cm}$ thickness are located narrowly. In some index horizon, the lens shaped conglomerate is observed. In the sedimentary structure, mud crack and 

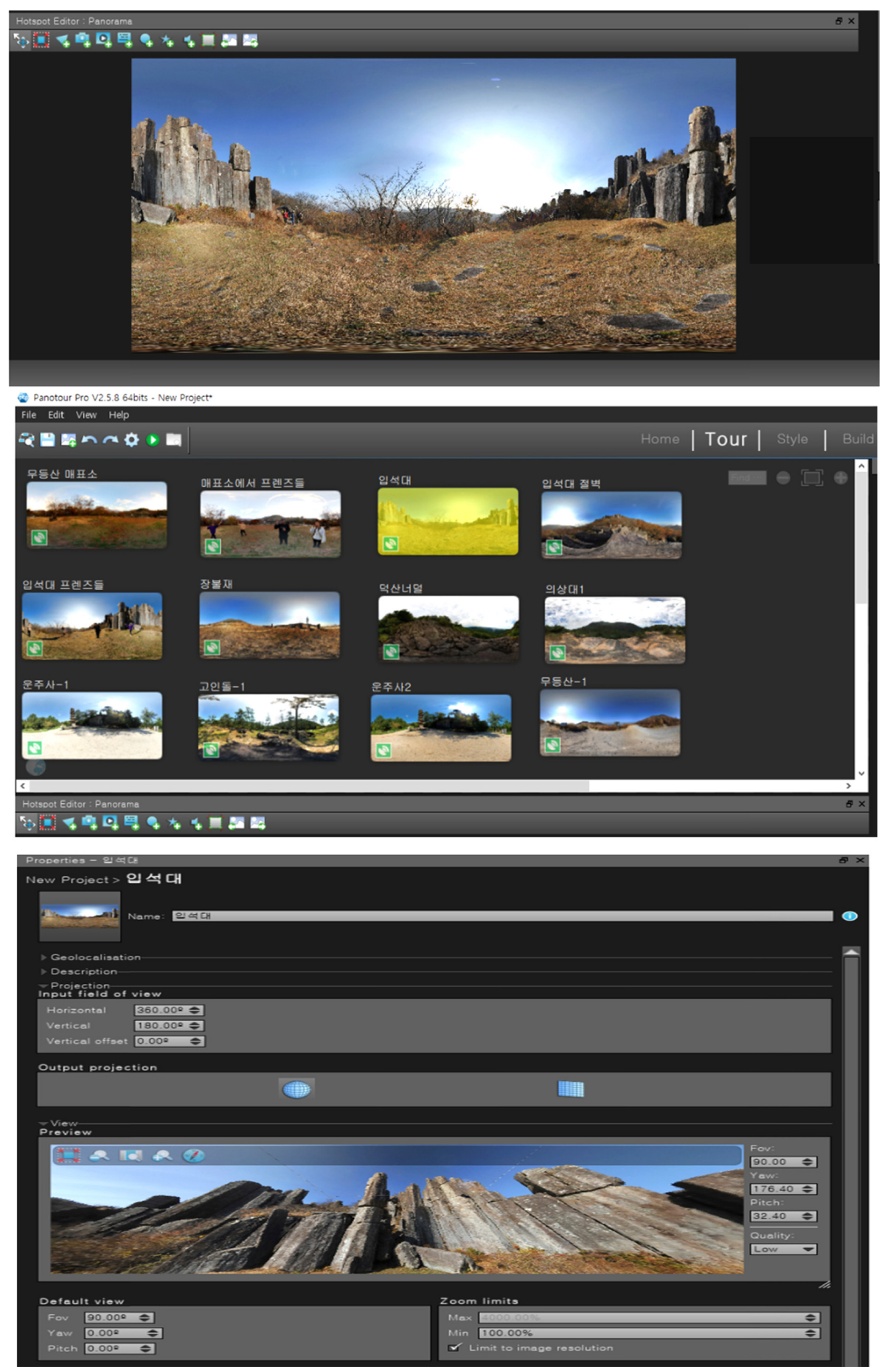

Figure 3. Panotour Pro is a program that allows you to create impressive 360-degree virtual tours and offer a unique experience to the virtual geological field trips on the website or SNS (Social Networking Service) account with mobile phone or PC. In addition, this software can mix photo content with sounds and videos to create stunning interactive educational commentary such as YouTube.

ripple mark are observed. The Cretaceous period's palaeo-environmental in Seoyu-Ri, Hwasun is interpreted as an environment that reaches to lake floor of shallow-water from mud or sand plains near lake side. Seeing the rare development of calcareous relict soil, it is judged that the environment of the lake was weak in general, rainfall was high, and sedimentation speed would be also fast, at the time of formation of sedimentary layers (Huh et al., 2003).
In addition, in the Jangdong layer of Cretaceous period, located in Maeng-Ri and Ok-Ri, Buk-Myeon, Hwasun-Gun, Jeonnam-Do, evaporation residual minerals trace, indicating the presence of high salinity lake and mudflat in the vicinity of the lake during deposition, were reported (Huh et al., 2003; Paik et al., 2010). The development of sedimentary records that indicate the presence of quite high-salinity water in the Jangdong layer where fossils of dinosaur footprints are produced implies that dinosaurs and pterosaurs in the Cretaceous period drank quite high-salinity water to quench their thirst in drought, which has an academic value in providing the palaeo-environmental and palaeo-ecological information in the dinosaur era (Huh et al., 2003).

By K-Ar absolute age measurement, the andesite in the lower portion of fossil index horizon was measured as $81.4 \pm 1.6 \mathrm{Ma}$, and the andesite of Mt. Mudeung covered on Jangdong stuff with non-conformity was measured as $76.7 \pm 1.7 \mathrm{Ma}$. This indicates that the sedimentary layer of fossil site in Seoyu-Ri is the late Cretaceous period (Kim and Kang, 2012).

Hwasun Dinosaur Fossil Site is a geologically famous place with very great academic value, which is observed not only very high density dinosaur footprints and trackways, but also a number of dinonychosaur footprints with the lowest proportion among dinosaur footprints. It also shows the ecological diversity of the Cretaceous period through small sized pterosaurs footprints. The site has already been designated as a natural monument since its academic value has been proven in existing researches, and also been listed as a candidate site for UNESCO's World Natural Heritage list. In fossil site, a various signboards and miniatures, including information centers, helping visitors understand the fossil site. As the geo-trail of this site, first, there is a dinosaur fossil site, and second, there is an evaporite region where evaporation residual minerals are produced. All of this 3D panoramic virtual reality (PVR) program is available from a website (http:// 203.253.36.216/hskim/panorama/dino/dinofloor.html) by PCs or smartphones and be freely rotated and zoomed.

\section{Unjusa Temple Stratiform Tuff}

The geologic features of the Hwasun Unjusa Temple region are made of the Cretaceous period tuff, and in these outcrop, the stratification bedding is developing with the lapili tuff. This site was formed around the crater when viewed by pyroclastic deposits and statifica- 
tion bedding surfaces, and records of explosions and resting phase are well remained on the statification bedding surface (Park et al., 2008).

In the temple, tuff cliff outcrops with several meters-high is appeared, as several large and small statues placed in front of them, it creates a more mysterious atmosphere. The stone works, including the Buddha statue, of Unjusa Temple, were made during the Goryo Dynasty and were all made of nearby tuff without exception.

Unjusa Temple Stratiform Tuff is a layer formed in the Cretaceous period and the outcrop is a green gray laffili tuff with advanced Stratification bedding, which stabilizes the major stratification bedding surfaces and split them into several $\mathrm{cm}$ thicknesses. The substrate of tuff has extremely poor sorting, and the crests are mainly tuff or rhyolite and almost size of lapilli, but also include large sized rock fragments up to several tens of $\mathrm{cm}$. Almost all rock fragments are angulated, and in general, they are weak and not dense to weathering. When entering a little more, tuff cliff outcrops with several meters-high are appeared, and several large and small Buddha statues are lied in front of them. These Buddha statues are also made of tuff. The stratiform tuff around Unjusa Temple was filed around volcanoes, or crater, by volcanic eruptions that erupted pyroclastic deposits (volcanic ash, lapili, volcanic rock blocks, etc.) in large volume, and the time between the eruptions is remained as a major stratification bedding surfaces that records break of sedimentation or erosion (Park et al., 2008).

Unjusa Temple Stratiform Tuff has its great value as a geologic famous place that can observe the stratiform tuff outcrop formed by the volcanic eruption of Cretaceous period. Various pyroclastic deposits and statification bedding surfaces, such as volcanic ash, lapili, and volcanic rock blocks, are good evidence of how volcanic activity was performed at that time. In general, it is also shaped that outcrop surrounds the temple, resulting an excellent scenic value, and the stone Buddha statue is made of tuff here, indicating that the tuff here has been used historically. All of this 3D panoramic virtual reality (PVR) program is available from a website (http://203.253.36.216/hskim/ panorama/unjusa/tour.html) by PCs or smartphones and be freely rotated and zoomed.

\section{Hwasun Dolmen Site Jangdong tuff}

In Hwasun Dolmen Site Jangdong tuff, there are 5 querries that tore off cover stone, which was a necessary material for building Dolmen during the Bronze Age, from the tuff outcrop corresponding to the Cretaceous period Jangdong tuff. Quarry is in the form of an outcrop, and judged from the distribution of the scattered dolmen, it is shown that separated rocks were used as dolmen. It is judged that research value is high in geologically and historically as various dolmen are distributed around it (Huh et al., 2006).

Dolmen Site of Hwasun is Historic Site No. 410 and is a place of southern style Dolmen, the representative tomb style of the Bronze Age, which is also a site of dolmen size and high density worldwide. Except for this, various relics have been excavated, including the discovery of a bowl-shaped grinded stone sword. According to this value, it is listed as a UNESCO World Heritage site. Daesin-Ri and HyosanRi of Hwasun have 319 and 277 Dolmens respectively, and a total of 596 Dolmens, especially, dozens of Dolmen over 100 tons and "Pingmae Rock", the world's largest dolmen with over 200 tons.

The outcrop of Hwasun Dolmen Site Jangdong tuff is all made up of tuff. Hwasun Dolmen Site is a region belonging to the Cretaceous period Jangdong tuff on geological map. The Jangdong tuff is the tuff of the assembly containing the sharpstones. The phenocryst is mainly plagioclase and quartz, and phenocrysts are filled with fine-grained glassy stoneware (Huh et al., 2006).

There are 5 outcrops totally used as quarry, and the height of outcrop is 40 to 50 meters, and the length reaches 2 kilometers. The most prominent outcrop quarry is 3 places: Madang Rock, Gaksi Rock, and Gamtae Rock. As the traces of a wedge to make the Dolmen has left in the quarry, it shows that the rock was separated and moved from here. However, seeing from rocks of different shapes and sizes are distributed without a certain format, it is assumed that it may have dug in hole and used rock blocks, separated from the outcrop due to weathering, scattered across the slopes and plains, as tombs. It was revealed through the previous researches that there are about 596 dolmens made up of these tuff rock blocks and many of them were tombs (Huh et al., 2006).

Hwasun Dolmen Site Jangdong tuff is a place where Dolmen, wellknown for the past burial culture, was made using tuff. This site is well observed place for the Cretaceous period tuff outcrop as well, and has more valuable due to the fact that this outcrop was used as quarry at the time. Dolmens in Dolmen Site was all made through Jangdong tuff, and hence, is judged as a geological famous place which is valuable geologically and historically. All of this 3D panoramic virtual reality (PVR) program is available from a website (http://203.253.36.216/ hskim/panorama/goindol/tour.html) by PCs or smartphones and be freely rotated and zoomed.

\section{VFT Educational Effects}

We divided the Mudeung UNESCO Global Geopark into 6 districts and captured images from each to compose and develop a continuous tour; All of them represented the main geological and geographical regions of interest.

The main screen primarily features the panoramic image and a user menu (Fig. 4). The menu includes "preparation studies", "observation studies", and "organization studies" buttons. The first contains preliminary information regarding the geology and geography of the Mudeung UNESCO Global Geopark, the second connects to the actual cyber tour screen, and the third connects to further information intended to complement the active experience. Other menu buttons allow the user to zoom, scroll, lock screen orientation, play or stop audio files, access a help function, and toggle a full-screen mode. The left side of the screen shows the 6 primary districts and the right side shows the list of tour locations to enable easy navigation. Thus, the learner can explore the tour step by step by selecting different locations to observe. On the middle left of the screen, there is a map button that toggles a Google Map of the area. Every screen shows the current view direction; a compass located in the middle of the screen identifies the direction of the strata. A draggable interactive $\mathrm{w}$ allows learners to measure the slope of the strata.

The main features of our developed VFT program can be summarized as follows. First, geological field trip locations can be easily navigated in the online interface, allowing the learner to choose the order in which they visit sites. Second, information on the specific observation location is provided through pop-ups, narration, close-up 

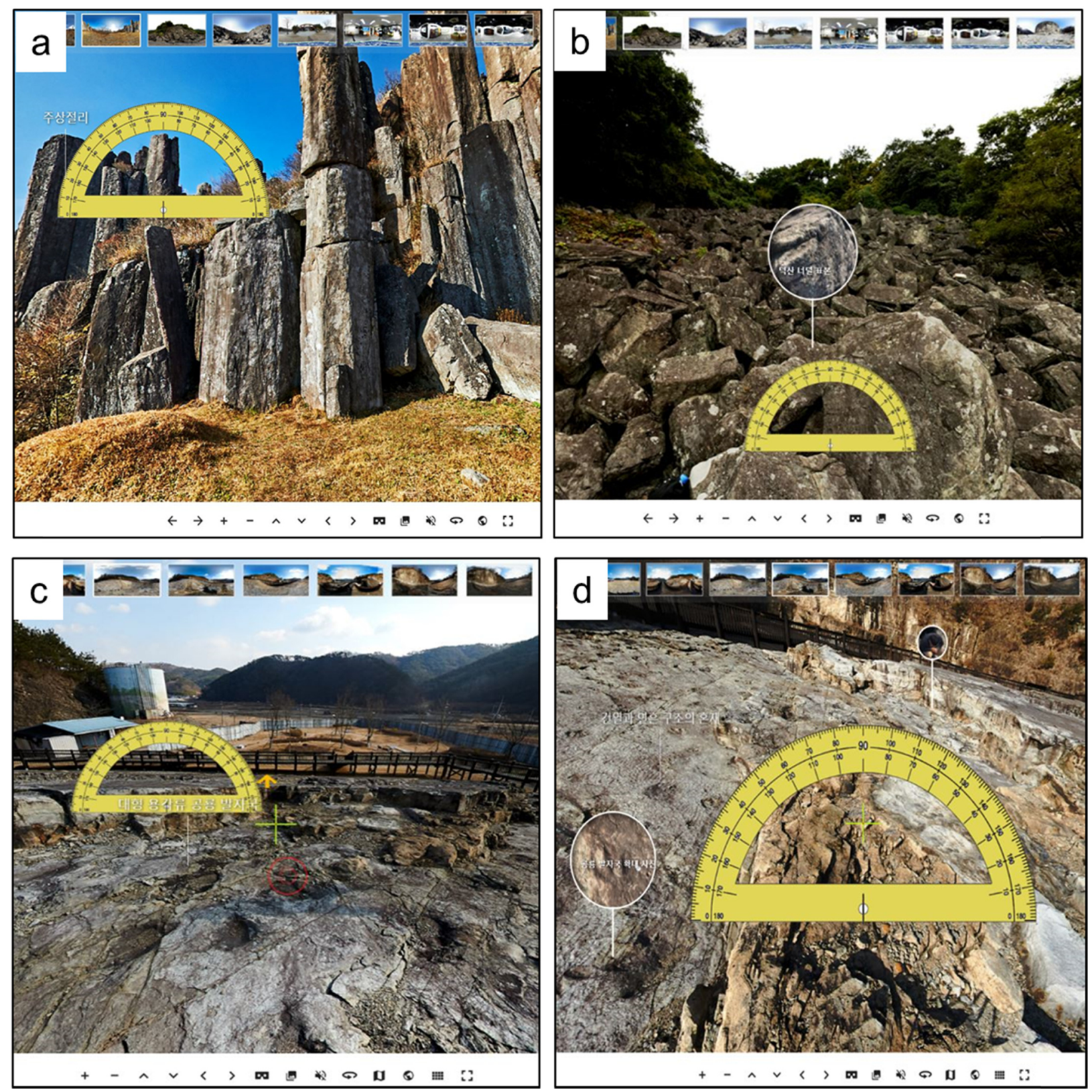

Figure 4. Example of the PVR learning scene. With 3D Panoramic Virtual Reality, the cyber-educators in the Earth Sciences are free to explore the educator's design for the geological field area merely using the mouse to roam around and clicking on pre-defined Hot-spot to jump from one place to another. Hot-spot a; the columnar joint in Mt. Mudeung, Hot-spot b; Deoksan Stony Slope, Hot-spot c and d; Hwasun Dinosaur Fossil Site.

photos, and detailed explanations, providing support for specific assigned activities. Third, the compass feature identifies the direction of the strata and the draggable protractor allows the angle measurements. Fourth, selected samples from the main observation spots can be zoomed in on and rotated, indirectly providing the experience of actual field observations.

The following are the features and information regarding topology observation, stratum observation, sample observation in the developed 6 areas and ten main observations spots (Park et al., 2008).

\section{Topology Observation}

The developed $360^{\circ} \times 180^{\circ} 3 \mathrm{D}$ panorama contains all possible views from the observation area. To carry out a virtual geological field trip, the entire observation area must be observed by using the mouse or navigation button to rotate left and right (the view is set at $90^{\circ}$ by default). The left-hand Google Map window allows observation of the area from the top in order to identify the overall location and study the overall strata (Fig. 5). This may enhance learners' spatial ability (Tan et al., 2006; Park et al., 2008; Heo and Lee, 2013).

One of the main activities in the VFT is measuring the direction and slope of strata. During development, this was enabled by setting these data within the panorama in advance. Another activity involves using a loupe to observe specific rock samples carefully. This was enabled by producing $3 \mathrm{D}$ examples of samples and related rocks for each observation area that could be rotated and zoomed in and out. At 

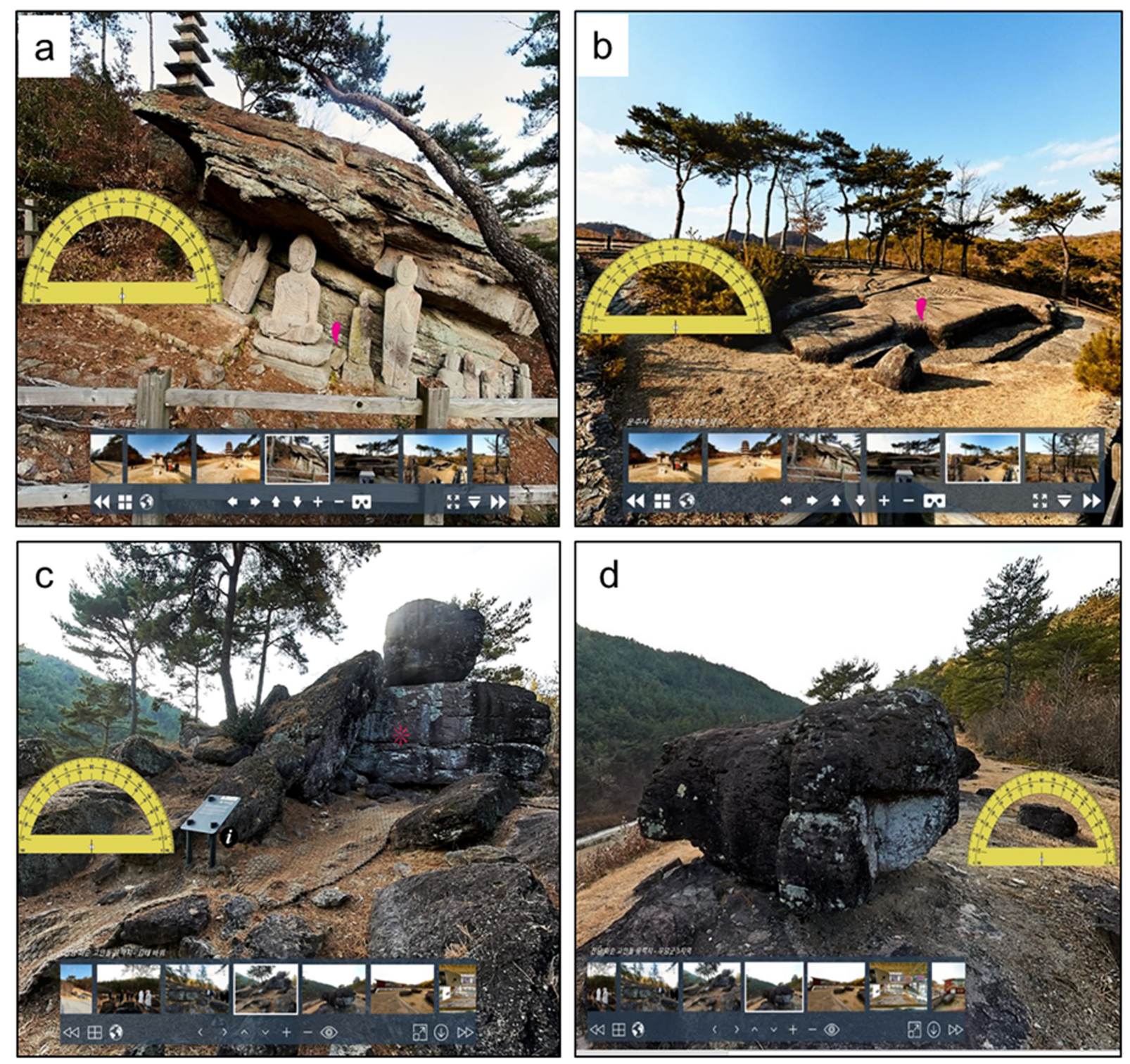

Figure 5. Example of the PVR learning scene. With 3D Panoramic Virtual Reality, the cyber-educators in he Earth Sciences are free to explore the educator's design for the geological field area merely using the mouse to roam around and clicking on pre-defined Hot-spot to iump from one place to another. Hot-spot a and b; Unjusa Temple Stratiform Tuff, Hot-spot c and d; Hwasun Dolmen Site Jangdong tuff.

points where such features are available, links to educational material or further explanations are provided. Where expert explanation is needed, this is provided through narration or video.

\section{Testing the VFT}

We tested our VFT on 25 teachers undergoing a month-long training in cyber-education at the Earth Sciences Education department, because we expected that teachers would provide honest and useful feedback given their knowledge of and interest in science education. The teachers first accessed the program on PC or smartphones. After a tutorial on basic learning methods, they conducted observations within the VFT. Their first observation activity was to click the "preparation studies" button to access introductory materials. Second, they pressed the "observation" button to begin active observations, follow the program contents to learn in order or individually navigating to specific locations. In this phrase they viewed the scenery, surrounding strata, geological structure, and other features. At geologically or geographically unique spots, they accessed pop-up narrations, rotated and magnified samples in 3D, listened to expert explanations, and zooming in on images to access relevant information (Kent et al., 1997; Dykes et al., 1999). Finally, they undertook the organization stage in which observational outcomes were assessed, focusing on geographical and geological structures reflecting on their learning.

To assess user responses to the program, we developed a survey addressing 13 criteria following Orion and Hofstein $(1991,1994)$ and had it reviewed by two geological experts, two education experts, and five earth science lecturers with regard to its suitability. The approved survey was then given to the teachers who had tested the program (Table 1).

The response column indicates the number given by the 25 students, and the overall grade for the response was shown in percentage. Here, 
Table 1. Response Survey responses from teachers after testing theresults of virtual filed field trip, () is response level

\begin{tabular}{|c|c|c|c|c|c|c|c|}
\hline \multirow{2}{*}{ Item } & \multirow{2}{*}{ Survey contents } & \multicolumn{5}{|c|}{ Response $^{(a)}$} & \multirow{2}{*}{$\%$} \\
\hline & & 1 & 2 & 3 & 4 & 5 & \\
\hline Relation of curriculum & This VFT is included a lot of contents related geology curriculum & & & 1 & 12 & 12 & 89 \\
\hline Leaning objective & This VFT can be helped to achieve geological learning objective & & & 4 & 12 & 9 & 84 \\
\hline Comprehension & This VFT was helpful to understand geological knowledges & & & 3 & 11 & 11 & 86 \\
\hline Memory & The contents learned in the VFT will be long memorized & & & 3 & 11 & 11 & 86 \\
\hline Ineteresting & This VFT is interesting & & & & 10 & 15 & 92 \\
\hline Sense of beauty for nature & I could feel the beauty of nature through the VFT & & & 3 & 12 & 10 & 86 \\
\hline Usefullness & $\begin{array}{l}\text { The VFT is a good method to learn geology. So I want to paticipate in } \\
\text { another VFT }\end{array}$ & & & 4 & 10 & 11 & 86 \\
\hline Easy of use & The VFT is easy to use. & & & & 6 & 19 & 95 \\
\hline Self-directed learning & I alone can learn the contents of VFT & & & 1 & 9 & 14 & 87 \\
\hline Interaction & This VFT is inreractive & & & 1 & 11 & 13 & 90 \\
\hline Similarity for reality & This VFT is similar to real environment & & & 2 & 8 & 15 & 90 \\
\hline Fusion education & The VFT is included a lot do other learning contents & & & & 10 & 15 & 92 \\
\hline Expandability & I want to learn the fossil VFT or the plant VFT using 3D panorama & & & & 8 & 17 & 94 \\
\hline
\end{tabular}

(a) 1 strong disagree; 2 disagree; 3 neutral; 4 agree; 5 strongly agree

over $89 \%$ of respondents were positive about the program's relevance to the educational process, learning outcomes, and understanding. As shown by Stephen (1998), this response could have resulted from the use of supplementary information that enhances student observation and understanding of specific geological phenomena. However, it is thought that such VFT classes should be supplementary to the traditional classes (Caliskan, 2011). 92\% gave positive responses to interest and appreciating the beauty of nature, suggesting that this program can provide an opportunity for the students who otherwise lack exposure to nature to have these experiences; this was similar to results reported by Uricchio (2011). Maximizing the link between natural beauty and learning materials in the VFT program may enhance moral education. For efficiency, around $84 \%$ were positive with regard to the ease of learning geological materials through the VFT given the ability to repeat visits, reduce time and cost, and lack of safety concerns. $86 \%$ were positive with regard to convenience.

VFT programs are easy to use by freely allowing learning on smartphones or PCs (Allison and Cuffey, 2012); this is reflected by the $95 \%$ positive reviews regarding independence given our program's ability for students to learn and tour independently through many navigation options. $90 \%$ of learners responded that interaction with the program was natural, because learners can access, magnify, and rotate 3D features while navigating freely with detailed guidance. $90 \%$ were positive regarding the realistic nature of the program, possibly because the sites were captured by real cameras (not modeled). However, there are still observational limitations to such VFTs, such as the inability to touch or smell real features (Qiu and Hubble, 2002). Integrated education was seen as $92 \%$ positive; although the core contents of the VFT was geology-orientated, its features also included scenery, plants, and animals, building connections between nature and humans. Finally, 94\% suggested the expansion and implementation of such VFT programs in other nature education.

As in the results of Spicer and Stratford (2001), the VFT developed here received positive responses overall, suggesting that such PVR classes can be an alternative educational method where live geological field trips cannot be arranged. In the future, we intend to continue developing the structure and composition of this program to allow analysis of field observations and expand its scope to cover plants or fossils.

\section{Conclusion and Proposal}

The Mudeung UNESCO Global Geopark of the terrain include dinosaur footprints and the attractive Hwasun cliff of the Jangdong Formation, columnar joint, the block stream of the Mudeung Tuff formed by affected by freezing and thawing under periglacial climate. The columnar joints of Mt. Mudeung have been exposed to the ground surface since 110,000 years to 50,000 years ago. The separation of blocks formed the block streams from the vertical cliff. Therefore, this area represents the Mesozoic igneous activity in Korean peninsula and can act as an excellent site of geological education.

The 3D VFT program we developed for the Mudeung UNESCO Global Geopark received over $89 \%$ positive feedback from the teachers who tested it. This response demonstrate that VFT-based learning can be a useful replacement for actual field trips when difficulties in arranging the latter are present for schools and universities; this approach also provides virtual learning opportunities. Exposing students to the beauty of nature through VFTs has both educational and moral effects in in helping develop healthy views on the natural world through such integrated education. Easy access to VFTs through smartphones and PCs raises the potential for expansion to other fields, such as plants or fossils. Producing such geological field works observations in VFT and collating them in one place can be used in teaching science at the elementary, middle, high school, and university levels in order to maximize the educational effect and reduce time and costs. 


\section{Acknowledgements}

This work was financially supported by the National Research Foundation of Korea (NRF-2016R1D1A1B01010469).

\section{References}

Ahn, K.S., 2010, Geology and Landscape of Mt. Mudeung Province Park, Korea. The Journal of the Petrological Society of Korea, 19(2), 109121. (in Korean)

Allison, K., and Cuffey, K., 2012, Virtual field trip for introductory geoscience classes. The California Geographer, 52, 1-18.

Caliskan, O., 2011, Virtual field trips in education of earth and environmental sciences. Procedia Social and Behavioral Sciences, 15, 32393243.

Cha, M.S., 1988, Cretaceous volcanic cauldrons and ring complexes in Korea. Journal of Geological Society of Korea, 24, 67-86. (in Korean)

Cheon, J.B. and Kim, H.S., 2018, Comparison of Class Effect of Real Field Trip and Virtual Field Trip, The Korean Society and School Science, 12, 331-340. (in Korean)

Dykes, J., Moore, K., and Wood, J., 1999, Virtual environments for student fieldwork using networked components. International Journal of Geographical Information Science, 13, 397-416.

Heo, J.H., and Lee, K.Y., 2013, The effects of flash panorama-based virtual field trips on students' spatial visualization ability and their understanding of volcanic concept in high school earth science class. Journal of the Korean Earth Science Society, 34, 345-355. (in Korean)

Huh, M., Paik, I.S., Chung, C.H., Hwang, K.G., and Kim, B.S., 2003, Theropod tracks from Seoyuri in Hwasun, Jeollanamdo, Korea: occurrence and paleontological significance. Journal of the Geological Society of Korea, 39, 461-478. (in Korean)

Huh, M., Paik, I.S., Lockley, M.G., Hwang, K.G., Kim, B.S., and Kwak, S.K., 2006, Well-preserved theropod tracks from the Upper Cretaceous of Hwasun County, southwestern South Korea, and their paleobiological implications. Cretaceous Research, 27(1), 123-138.

Hurst S., 1998, Use of "virtual" field trips in teaching introductory geology. Computer and Geosciences, 24, 653-658.

Kent, M., David, D., and Chris, O., 1997, Fieldwork in geography teaching: A critical review of the literature and approaches. Journal of Geography in Higher Education, 21, 313-332.

Kim, C.B., and Kang, S.S., 2012, K-Ar Ages of Cretaceous Fossil Sites, Seoyuri, Hwasun, Southern Korea. Journal of the Korean earth science society, 33(7), 618-626.

Kim, G.W. and Lee, K.Y., 2011, Development web-based virtual geological field trip by using flash panorama and exploring the ways of utilization: A case of Jeju island in Korea. Journal of the Korean Earth Science Society, 32, 212-224. (in Korean)

Kim, H.S., 2014, Development and application of virtual geological field trip program using 3D panorama virtual reality technique. Journal of the Korean Earth Science Society, 35(3), 180-191. (in Korean)

Kim, H.S., Ham, H.S and Lee, M.W., 2013, Development and application of geological field study sites in the area of igneous rocks. Journal of the Korean Earth Science Society, 34(3), 274-285. (in Korean)

Kim, Y.J., and Lee, C.B., 1988, The study of igneous rocks and their igneous activity in the JangsooUnbong area. Journal of Geological Society of Korea, 24, 111-131. (in Korean)

Kim, Y.J., Oh, M.S., and Park, J.B., 1993, Petrochemical study on the Kwangju granite body. Economic and Environmental Geology, 26(1), 83-96.

Lim, C., Huh, M., Yi, K., and Lee, C., 2015, Genesis of the columnar joints from welded tuff in Mount Mudeung National Geopark, Republic of Korea. Earth, Planets and Space, 67(1), 152.
Ministry of Education, 2011, Science curriculum. Seoul, Korea, 8 p. (in Korean)

Oh, J.J., Park, S.P., and Seong, Y.B., 2012, Type and characteristics of debris landform in Mt. Mudeung. Journal of the Korean association of regional geographers, 18(3), 253-267. (in Korean)

Orion, N. and Hofstein, A., 1991, The measurement of students' attitudes towards scientific field trips. Science Education, 75, 513-523.

Orion, N. and Hofstein, A., 1994, Factors that influence learning during a scientific field trip in a natural environment. Journal of Research in science Teaching, 31, 1097-1119.

Park, B.K., Kim, Y.J., and Kim, Y.J., 2005, A minerlogical study of plagioclase in volcanic rocks from the Mt. Mudeung Area. Journal of the Mineralogical Society of Korea, 18(3), 155-164. (in Korean)

Paik, I.S., Kim, H.J., and Huh, M., 2010, Impressions of dinosaur skin from the Cretaceous Haman Formation in Korea. Journal of Asian Earth Sciences, 39(4), 270-274.

Park, J., Carter, G., Butler, S., Slykhuis, D., and Reidgriffin, A., 2008, Redimensional thinking in Earth Science: Form 3-D virtual reality panoramas to 2-D contour maps. Journal of Interactive Learning Research, 19, 75-90.

Park, S.M., Lee, M.S., Choi, S.W., and Lee, C.H., 2008, Material Characteristics and Deterioration Assessment of the Stone Buddhas and Shrine in Unjusa Temple, Hwasun, Korea. Journal of Conservation Science, 24, 23-36.

Qiu, W. and Hubble, T., 2002, The advantages and disadvantages of virtual field trips in geoscience education. The China Papers, October, 75-79.

Spicer, J. and Stratford, J., 2001, Student perceptions of a virtual field trip to replace a real field trip. Journal of Computer Assisted Learning, 17, $345-354$.

Stephen, D., 1998, Use of 'virtual' field trips in teaching introductory geology. Computers \& Sciences, 24, 653-658.

Tan, A., Timmermans, H., and Vries, B., 2006, Route knowledge in complex environments: An analysis of pedestrian recall using stereoscopic panoramic interactive navigation. Spatial Cognition and Computation, 6, 279-293.

Uricchio, W., 2011, A 'proper point of view': The panorama and some of its early media iterations. Early Popular Visual Culture, 9, 225-238.

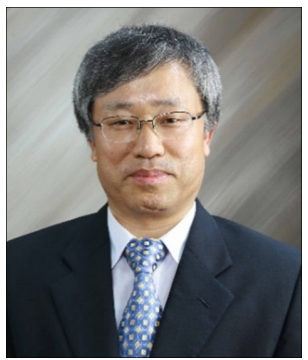

Hee-Soo Kim is a full professor of Science Education of the Teachers College at Kongju National University, Korea. He received his Ed.D. from Korea Teachers University, Choongbuk, Korea. He has been studying 'Science Education and Virtual Reality' more than 20 years in Korea since he joined Kongju National University in 1996. He is editor and director of the Journal of Korean Society of Earth Science Education, director of the Journal of the Korean Earth Science Society.

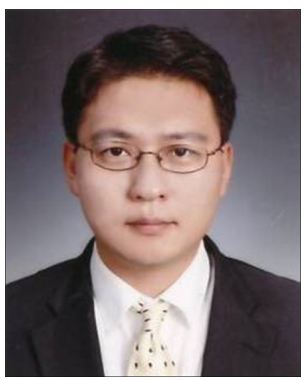

Chungwan Lim is an Assistant Professor in the Department of Earth Science Education, Kongju National University. He received a B.S. (1998) from Chonbuk National University, an M.S. (2002) from Seoul National University, and a Ph.D. (2008) from Hokkaido University in Japan. He was a Research Scientist at the University of Iowa in the USA from 2009 to 2011. He had been worked as a postdoctoral researcher and as a BK21 Assistant Professor at Seoul National University (2011-2018). Currently, he is interested in the application of Virtual Geological Field Trip (VFT) Program using the 3D Panorama Virtual Reality Technique. 